\title{
TiC Nanoparticle Addition to Enhance the Mechanical Response of Hybrid Magnesium Alloy
}

\author{
Muralidharan Paramsothy, ${ }^{1}$ Jimmy Chan, ${ }^{2}$ Richard Kwok, ${ }^{2}$ and Manoj Gupta ${ }^{1}$ \\ ${ }^{1}$ Department of Mechanical Engineering, National University of Singapore, 9 Engineering Drive 1, Singapore 117576 \\ ${ }^{2}$ CTO Office, Singapore Technologies Kinetics Ltd (ST Kinetics), 249 Jalan Boon Lay, Singapore 619523
}

Correspondence should be addressed to Manoj Gupta, mpegm@nus.edu.sg

Received 8 August 2011; Revised 29 September 2011; Accepted 3 October 2011

Academic Editor: Jaime Grunlan

Copyright ( 2012 Muralidharan Paramsothy et al. This is an open access article distributed under the Creative Commons Attribution License, which permits unrestricted use, distribution, and reproduction in any medium, provided the original work is properly cited.

\begin{abstract}
A hybrid magnesium alloy nanocomposite containing TiC nanoparticle reinforcement was fabricated using solidification processing followed by hot extrusion. The nanocomposite exhibited similar grain size to the monolithic hybrid alloy, reasonable TiC nanoparticle distribution, nondominant $\left(\begin{array}{llll}0 & 0 & 0 & 2\end{array}\right)$ texture in the longitudinal direction, and 16\% higher hardness than the monolithic hybrid alloy. Compared to the monolithic hybrid alloy, the nanocomposite simultaneously exhibited higher tensile yield strength $(0.2 \%$ TYS), ultimate tensile strength (UTS), failure strain, and work of fracture (WOF) $(+14 \%,+7 \%,+81 \%$, and $+92 \%$, resp.). Compared to the monolithic hybrid alloy, the nanocomposite exhibited lower compressive yield strength $(0.2 \%$ CYS $)$ and higher ultimate compressive strength (UCS), failure strain, and WOF $(-11 \%,+7 \%,+4 \%$, and $+15 \%$, resp.). The advantageous effects of TiC nanoparticle addition on the enhancement of tensile and compressive properties of the hybrid magnesium alloy are investigated in this paper.
\end{abstract}

\section{Introduction}

The AZ (aluminium-zinc) series of magnesium alloys are commonly used in structural applications due to (a) low cost, (b) ease of handling, (c) good strength and ductility, and (d) resistance to atmospheric corrosion [1]. These magnesium alloys are commonly denoted by AZXY where $\mathrm{X}$ and $\mathrm{Y}$ indicate the nominal weight contents of aluminium (A) and zinc $(\mathrm{Z})$ in the alloy (resp.). AZ31 has been surface-reinforced with $\mathrm{SiC}$ microparticulates [2], $\mathrm{C}_{60}$ molecules [3], and multiwalled carbon nanotubes [4] using the friction stir processing technique. Here, it was reported that hardening of the base matrix at the surface occurred due to good particle dispersion. Yttrium has been added to AZ61 to increase its dry oxidation resistance [5]. The solidification processing parameters used were (1) stirring temperature, (2) velocity, and (3) time where the alloy was observed to sometimes consist of well-distributed fine circular phase [5]. AZ61- $\mathrm{SiO}_{2}$ nanocomposite surface has been obtained using friction stir processing [6]. Here, the tensile elongation at $350^{\circ} \mathrm{C}$ of selected composites reached $350 \%$ at $1 \times 10^{-2} \mathrm{~s}^{-1}$ and $420 \%$ at $1 \times 10^{-1} \mathrm{~s}^{-1}$. It was implied that sufficiently uniform dispersion of $\mathrm{SiO}_{2}$ nanoparticles resulted in high-strain-rate superplasticity (HSRSP) being exhibited [6]. However, the tensile elongation was barely $100 \%$ at the same temperature and at a lower strain rate of $1 \times 10^{-3} \mathrm{~s}^{-1}$ [6]. Regarding AZ91/SiC microcomposite, elevated temperature (250$400^{\circ} \mathrm{C}$ ) uniaxial compressive deformation behavior has been investigated [7]. A stress exponent of $n=5$ and a true activation energy of $Q=99 \mathrm{~kJ} / \mathrm{kmol}$ were obtained based on the effective stress dependence on strain rate and temperature [7]. This $Q$ value was close to that of grain boundary diffusion in $\mathrm{Mg}$, and the consequent conclusion was that dislocation climb controlled the elevated temperature compressive deformation [7]. Multiple layer microcomposites consisting of alternating layers of AZ91-coated P100 pitch-based fibers and AZ61 foil have also been studied [8]. It was observed that the reaction zone containing single and/or mixed metal carbides grew due to thermal treatment [8].

Regarding $\mathrm{TiC}$ reinforced composites, $\mathrm{TiC}$ and $\mathrm{TiB}_{2}$ have been used to reinforce each other via powder processing and sintering mainly, and this has been extensively reviewed [9]. 
Here, the effects of self-propagating high-temperature synthesis (SHS) processing route on microstructure and mechanical properties of the $\mathrm{TiC}^{-} \mathrm{TiB}_{2}$ composites has been reviewed [9]. Molten $\mathrm{Al}-\mathrm{Mg}$ alloys were infiltrated at $900^{\circ} \mathrm{C}$ into $\mathrm{TiC}$ preforms with flowing argon [10]. In this case, wetting of $\mathrm{TiC}$ substrates by the molten $\mathrm{Al}-\mathrm{Mg}$ alloys was investigated. It was observed that $\mathrm{Al}_{4} \mathrm{C}_{3}$ was selectively formed at the matrix-preform interface and $\mathrm{TiAl}_{3}$ traces were formed in the Al-based matrix. $\mathrm{La}_{2} \mathrm{O}_{3}$ and $\mathrm{TiC}$ were added to $\mathrm{W}$ for mechanical property improvement using vacuum hot pressing [11]. It was observed that the reinforcement particles pinned down the grain boundaries and inhibited the grain growth of $\mathrm{W}$ during sintering, resulting in matrix strengthening [11]. To a certain extent, $\mathrm{La}_{2} \mathrm{O}_{3}$ particles were beneficial for sintering and densification of composites while TiC particles exhibited good interfacial characteristics (for effective load transfer) with the adjacent $\mathrm{W}$ matrix [11]. It was observed that the collective strengthening effect of $\mathrm{La}_{2} \mathrm{O}_{3}$ and $\mathrm{TiC}$ particles on $\mathrm{W}$ was better than that of either $\mathrm{La}_{2} \mathrm{O}_{3}$ or TiC individually [11]. Elemental powders of Ti and $\mathrm{C}$ were formed into a preform where $\mathrm{TiC}$ was formed in situ [12]. Molten magnesium alloy AZ91D was pressurelessly infiltrated into this Ti-C perform, and tensile properties of the composite were compared to monolithic AZ91D [12]. Tensile strength (especially at higher temperatures) was enhanced by the in situ formed $\mathrm{TiC}$ reinforcement [12]. Compared to the strain hardening exponent $(n)$ of monolithic AZ91D being $0.11-0.32$, that of the AZ91D/TiC composite was higher at $0.71-0.82$ (for tensile deformation carried out at $423-723 \mathrm{~K}$ in each case) [12]. Technically, AZ31 may be alloyed with more pure aluminium to obtain the other more concentrated magnesium alloys in the AZ series. However, the mixing of two or more AZ series magnesium alloys for the same purpose (and consequent formation of a hybrid magnesium alloy) is also relevant. There may be certain advantages in this approach based on the lower liquidus temperature and lower melt density (during stirring/mixing) of the AZ series magnesium alloys compared to pure aluminium. Open literature search has revealed that no successful attempt has been made to simultaneously increase tensile strength and ductility of AZ31/AZ91 hybrid magnesium alloy with TiC or any other carbide nanoparticles, using a high-volume production spray-deposition-based solidification processing technique.

Accordingly, one of the primary aims of this study was to simultaneously increase tensile strength and ductility of AZ31/AZ91 hybrid magnesium alloy with TiC nanoparticles. Another aim of the present study was to evaluate the compressive properties of AZ31/AZ91/TiC hybrid alloy nanocomposite. Disintegrated melt deposition (DMD) $[13,14]$ followed by hot extrusion was used to synthesize the AZ31/ AZ91/TiC hybrid alloy nanocomposite.

\section{Experimental Procedures}

2.1. Materials. In this study, AZ31 (nominally 2.50$3.50 \mathrm{wt} \% \quad \mathrm{Al}, \quad 0.60-1.40 \mathrm{wt} \% \quad \mathrm{Zn}, \quad 0.15-0.40 \mathrm{wt} \% \quad \mathrm{Mn}$, $0.10 \mathrm{wt} \% \mathrm{Si}, 0.05 \mathrm{wt} \% \mathrm{Cu}, 0.01 \mathrm{wt} \% \mathrm{Fe}, 0.01 \mathrm{wt} \% \mathrm{Ni}$, balance $\mathrm{Mg}$ ) and AZ91 (nominally 8.30-9.70 wt $\%$ Al, 0.35-1.00 wt\% $\mathrm{Zn}, \quad 0.15-0.50 \mathrm{wt} \% \quad \mathrm{Mn}, \quad 0.10 \mathrm{wt} \% \quad \mathrm{Si}, \quad 0.030 \mathrm{wt} \% \quad \mathrm{Cu}$,
$0.005 \mathrm{wt} \% \mathrm{Fe}, 0.002 \mathrm{wt} \% \mathrm{Ni}, 0.02 \mathrm{wt} \%$ others, balance $\mathrm{Mg}$ ) both alloys supplied by Tokyo Magnesium Co. Ltd. (Yokohama, Japan), were used as matrix material. Equal masses of AZ31 and AZ91 were mixed to metallurgically upgraded AZ31. The intention of this mixing was to increase the nominal aluminium content of AZ31 by $3 \mathrm{wt} \%$. The average manganese $(\mathrm{Mn})$ content of the hybrid alloy $(0.17 \%)$ is slightly higher than that of AZ61 $(0.15 \%)$ based on handbook values [1]. $\mathrm{Mn}$ is the next important alloying element in $\mathrm{AZ}$ series magnesium alloys after $\mathrm{Al}$ and $\mathrm{Zn}$ (in that order). Also, the relatively lower compositional consistency of the hybrid alloy would not match the relatively higher compositional homogeneity in commercially available AZ61. AZ31 and AZ91 blocks were sectioned to smaller pieces. All oxide and scale surfaces were removed using machining. All surfaces were washed with ethanol after machining. TiC nanoparticles ( $98+\%$ purity, $30-50 \mathrm{~nm}$ size) supplied by Nanostructured and Amorphous Materials Inc (TX, USA) were used as the reinforcement phase.

2.2. Processing. Monolithic AZ31/AZ91 hybrid alloy (nominal aluminium content of AZ31 increased by $3 \mathrm{wt} \%$ ) was cast using the DMD method $[13,14]$. This involved heating AZ31 and AZ91 blocks to $750^{\circ} \mathrm{C}$ in an inert Ar gas atmosphere in a graphite crucible using a resistance heating furnace. The crucible was equipped with an arrangement for bottom pouring. Upon reaching the superheat temperature, the molten slurry was stirred for $2.5 \mathrm{~min}$ at $460 \mathrm{rpm}$ using a twin blade (pitch $45^{\circ}$ ) mild steel impeller to facilitate the uniform distribution of heat. The impeller was coated with Zirtex $25\left(86 \% \mathrm{ZrO}_{2}, 8.8 \% \mathrm{Y}_{2} \mathrm{O}_{3}, 3.6 \% \mathrm{SiO}_{2}, 1.2 \% \mathrm{~K}_{2} \mathrm{O}\right.$ and $\mathrm{Na}_{2} \mathrm{O}$, and $0.3 \%$ trace inorganics) to avoid iron contamination of the molten metal. The melt was then released through a $10 \mathrm{~mm}$ diameter orifice at the base of the crucible. The melt was disintegrated by two jets of argon gas oriented normal to the melt stream located $265 \mathrm{~mm}$ from the melt pouring point. The argon gas flow rate was maintained at $25 \mathrm{Lpm}$. The disintegrated melt slurry was subsequently deposited onto a metallic substrate located $500 \mathrm{~mm}$ from the disintegration point. An ingot of $40 \mathrm{~mm}$ diameter was obtained following the deposition stage. To form the AZ31/AZ91/ $1.5 \mathrm{vol} \% \mathrm{TiC}$ hybrid alloy nanocomposite, TiC nanoparticle powder was isolated by wrapping in $\mathrm{Al}$ foil of minimal weight $(<0.50$ wt $\%$ with respect to AZ31 and AZ91 total matrix weight) and arranged on top of the AZ31 and AZ91 alloy blocks (see Figure 1), with all other DMD parameters unchanged. All billets were machined to $35 \mathrm{~mm}$ diameter and hot extruded using 20.25:1 extrusion ratio on a 150 ton hydraulic press. The extrusion temperature was $350^{\circ} \mathrm{C}$. The billets were held at $400^{\circ} \mathrm{C}$ for $60 \mathrm{~min}$ in a furnace prior to extrusion. Colloidal graphite was used as a lubricant. Rods of $8 \mathrm{~mm}$ were obtained.

2.3. Heat Treatment. Heat treatment was carried out on all extruded sections at $200^{\circ} \mathrm{C}$ for 1 hour using a resistance heating furnace. This selection of temperature and time was made in order to relax the monolithic AZ31/AZ91 hybrid alloy (nominal aluminium content of AZ31 increased by 
TABLE 1: Results of grain characteristics and microhardness of AZ31/AZ91 and AZ31/AZ91/TiC nanocomposite.

\begin{tabular}{|c|c|c|c|c|}
\hline \multirow{2}{*}{ Material } & \multirow{2}{*}{$\mathrm{TiC}($ vol\%) } & \multicolumn{2}{|c|}{ Grain characteristics $^{\mathrm{a}}$} & \multirow{2}{*}{ Microhardness (HV) } \\
\hline & & Size $(\mu \mathrm{m})$ & Aspect ratio & \\
\hline AZ31/AZ91 & - & $5.1 \pm 0.7$ & 1.4 & $111 \pm 5$ \\
\hline AZ31/AZ91/1.5vol\% TiC & 1.50 & $4.0 \pm 1.0$ & 1.4 & $129 \pm 7(+16)$ \\
\hline
\end{tabular}

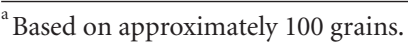

() Brackets: indicate \% change with respect to corresponding result of AZ31/AZ91.

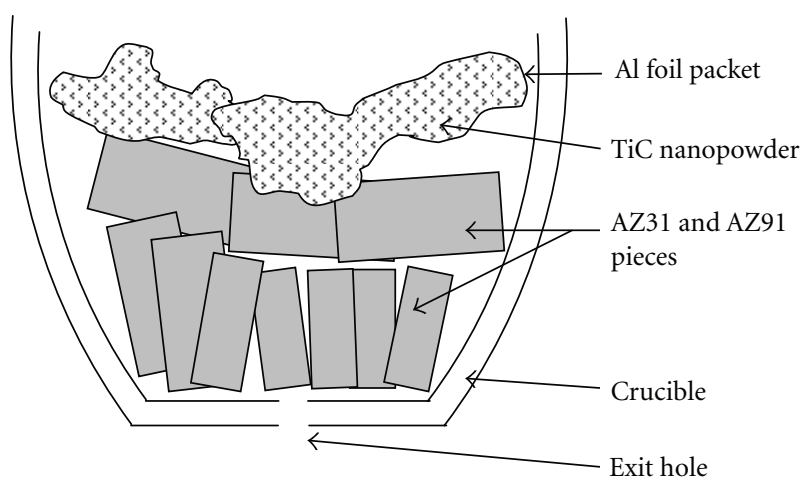

Figure 1: Arrangement of raw materials in crucible before casting for AZ31/AZ91/TiC nanocomposite.

$3 \mathrm{wt} \%$ ) without recrystallization softening. The recrystallization temperature of AZ61 magnesium alloy (as the nearest matching alloy in terms of composition) following $20 \%$ cold work after 1 hour is $288^{\circ} \mathrm{C}[1]$ ). Prior to heat treatment, the sections were coated with colloidal graphite and wrapped in aluminum foil to minimize reaction with oxygen present in the furnace atmosphere.

2.4. Microstructural Characterization. Microstructural characterization studies were conducted on metallographically polished monolithic and nanocomposite extruded samples to determine grain characteristics as well as nanoparticle reinforcement distribution. The etchant used was acetic picral [1]. Hitachi S4300 Field-Emission SEM was used. Image analysis using Scion software was carried out to determine the grain characteristics. XRD studies were conducted using $\mathrm{CuK}_{\alpha}$ radiation $(\lambda=1.5406 \AA)$ with a scan speed of $2^{\circ} / \mathrm{min}$ in an automated Shimadzu LAB-X XRD-6000 diffractometer to determine intermetallic phase(s) presence and dominant textures in the transverse and longitudinal (extrusion) directions.

2.5. Hardness. Microhardness measurements were made on polished monolithic and nanocomposite extruded samples. Vickers microhardness was measured with an automatic digital Shimadzu HMV Microhardness Tester using 25 gf-indenting load and $15 \mathrm{~s}$ dwell time.

2.6. Tensile Testing. Smooth bar tensile properties of the monolithic and nanocomposite extruded samples were determined based on ASTM E8M-05. Round tension test samples of $5 \mathrm{~mm}$ diameter and $25 \mathrm{~mm}$ gauge length were subjected to tension using an MTS 810 machine equipped with an axial extensometer with a crosshead speed set at $0.254 \mathrm{~mm} / \mathrm{min}$. Fractography was performed on the tensile fracture surfaces using Hitachi S4300 FESEM.

2.7. Compressive Testing. Compressive properties of the monolithic and nanocomposite extruded samples were determined based on ASTM E9-89a. Samples of $8 \mathrm{~mm}$ length ( $l$ ) and $8 \mathrm{~mm}$ diameter $(d)$, where $l / d=1$, were subjected to compression using an MTS 810 machine with $0.005 \mathrm{~min}^{-1}$ strain rate. Fractography was performed on the compressive fracture surfaces using Hitachi S4300 FESEM.

\section{Results}

3.1. Macrostructural Characteristics. No macropores or shrinkage cavities were observed in the cast monolithic and nanocomposite materials. No macrostructural defects were observed for extruded rods of monolithic and nanocomposite materials.

3.2. Microstructural Characteristics. Microstructural analysis results revealed that grain size and aspect ratio remained statistically unchanged in the case of nanocomposite as shown in Table 1 and Figures 2(a) and 2(b). TiC nanoparticle reinforcement and intermetallic particle distributions in the nanocomposite were reasonably uniform as shown in Figures 2(c), 2(d), and 2(e).

Texture results are listed in Table 2 and shown in Figure 3. In monolithic and nanocomposite materials, the dominant texture in the transverse and longitudinal directions was

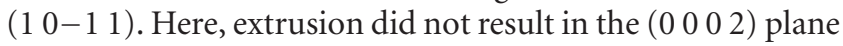
being intensely parallel to the extrusion direction (as we have previously reported) [15].

3.3. Hardness. The results of microhardness measurements are listed in Table 1. The nanocomposite exhibited higher hardness than the monolithic material.

3.4. Tensile Behavior. The overall results of ambient temperature tensile testing of the extruded materials are shown in Table 3 and Figure 4(a). The strength, failure strain, and work of fracture (WOF) of AZ31/AZ91/1.5vol\% TiC were higher compared to monolithic AZ31/AZ91. The WOF was determined by computing the area under the stress-strain curve up to the point of fracture. The fractured surface of all 


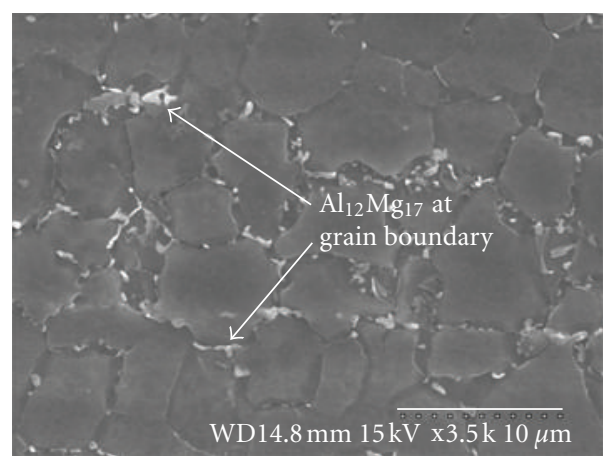

(a)

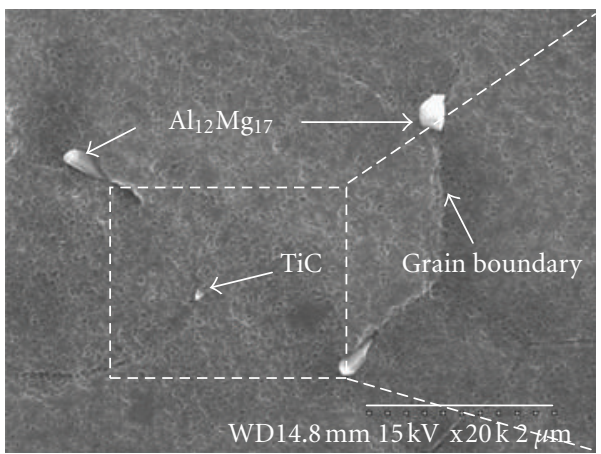

(c)

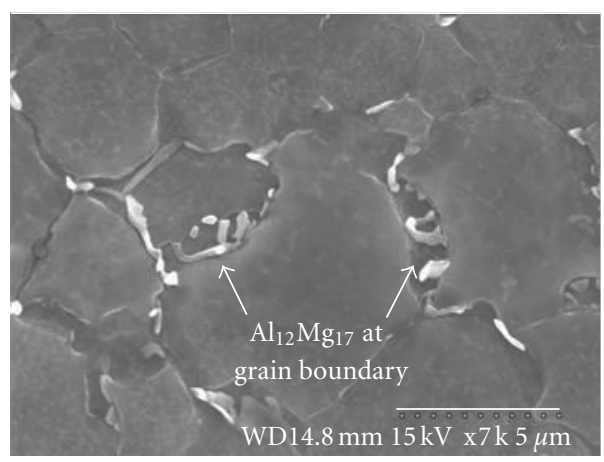

(b)

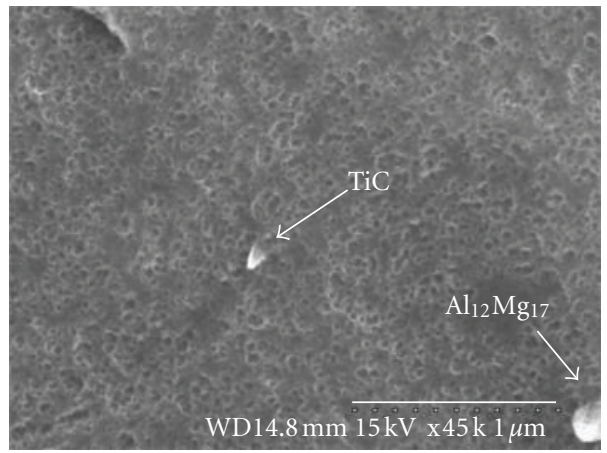

(d)

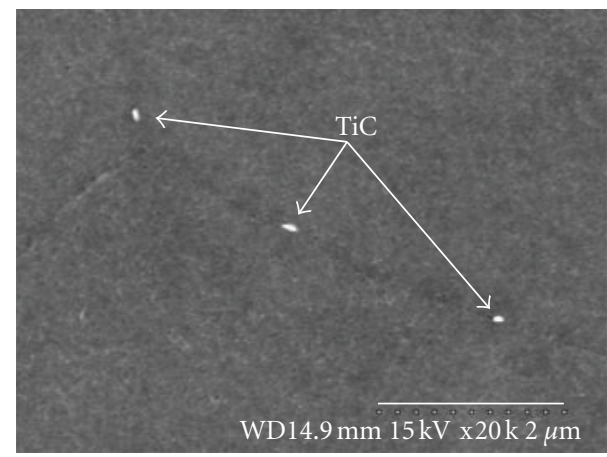

(e)

FIGURE 2: Representative micrographs showing grain size in monolithic AZ31/AZ91 and AZ31/AZ91/TiC nanocomposite: (a) lower magnification and (b) higher magnification. (c, d, e) Representative micrographs showing the presence of individual TiC nanoparticles and fine $\mathrm{Al}_{12} \mathrm{Mg}_{17}$ intermetallic particles in the AZ31/AZ91/TiC nanocomposite: (c, e) lower magnification and (d) higher magnification.

extruded materials exhibited mixed (ductile + brittle) mode of fracture as shown in Figures 5(a) and 5(b).

3.5. Compressive Behavior. The overall results of ambient temperature compressive testing of the extruded materials are shown in Table 4 and Figure 4(b). Comparing AZ31/ AZ91/1.5vol\% TiC to monolithic AZ31/AZ91, yield strength was lower and ultimate strength, failure strain, and WOF were each higher. The fractured surface of AZ31/AZ91/ $1.5 \mathrm{vol} \% \mathrm{TiC}$ and monolithic AZ31/AZ91 appeared similarly rough as shown in Figure 5(c).

\section{Discussion}

4.1. Synthesis of Monolithic AZ31/AZ91 and AZ31/AZ91/TiC Nanocomposite. Synthesis of monolithic and nanocomposite materials, the final form being extruded rods, was successfully accomplished with no detectable metal oxidation or reaction between graphite crucible and melts. The inert atmosphere used during DMD was effective in preventing oxidation of the $\mathrm{Mg}$ melt. No stable carbides of $\mathrm{Mg}$ or $\mathrm{Al}$ formed due to reaction with graphite crucible.

4.2. Microstructural Characteristics. Microstructural characterization of extruded samples is discussed in terms of (a) grain characteristics and (b) TiC nanoparticle reinforcement distribution.

Nearly equiaxed grains were observed in monolithic material and nanocomposite as shown in Table 1 and Figures 2(a) and 2(b). Grain size was statistically unchanged in the case of nanocomposite, suggesting the inability of $\mathrm{TiC}$ 
TABLE 2: Texture results of AZ31/AZ91 and AZ31/AZ91/TiC nanocomposite based on X-ray diffraction.

\begin{tabular}{|c|c|c|c|}
\hline Material & Section $^{\mathrm{a}}$ & Plane & Average $I / I_{\max }{ }^{\mathrm{b}}$ \\
\hline \multirow{6}{*}{ AZ31/AZ91 } & \multirow{3}{*}{$\mathrm{T}$} & $10-10$ prism & 0.53 \\
\hline & & 0002 basal & 0.26 \\
\hline & & $10-11$ pyramidal & 1.00 \\
\hline & \multirow{3}{*}{$\mathrm{L}$} & $10-10$ prism & 0.33 \\
\hline & & 0002 basal & 0.63 \\
\hline & & $10-11$ pyramidal & 1.00 \\
\hline \multirow{6}{*}{ AZ31/AZ91/1.5vol\% TiC } & \multirow{3}{*}{$\mathrm{T}$} & $10-10$ prism & 0.61 \\
\hline & & 0002 basal & 0.11 \\
\hline & & $10-11$ pyramidal & 1.00 \\
\hline & \multirow{3}{*}{$\mathrm{L}$} & $10-10$ prism & 0.32 \\
\hline & & 0002 basal & 0.65 \\
\hline & & $10-11$ pyramidal & 1.00 \\
\hline
\end{tabular}

${ }^{\mathrm{a}} \mathrm{T}$ : transverse; L: longitudinal.

${ }^{\mathrm{b}} I_{\max }$ is XRD maximum intensity from either prism, basal, or pyramidal planes.

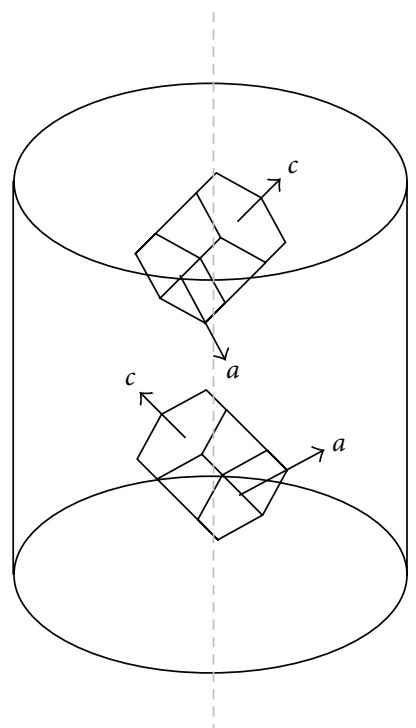

Figure 3: Schematic diagram showing textures of monolithic AZ31/AZ91 and AZ31/AZ91/TiC nanocomposite based on X-ray diffraction. In each case, vertical axis (dotted line) is parallel to extrusion direction. Each cell is made up of $2 \mathrm{HCP}$ units having 1

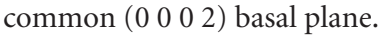

nanoparticles to serve as either nucleation sites or obstacles to grain growth during solid state cooling. It was observed that $\beta-\mathrm{Al}_{12} \mathrm{Mg}_{17}$ intermetallic particles decorated the grain boundaries in the monolithic material and nanocomposite. $\mathrm{X}$-ray diffraction (XRD) analysis revealed the presence of $\beta$ $\mathrm{Al}_{12} \mathrm{Mg}_{17}$ phase [15].

The reasonably uniform distribution of TiC nanoparticles as shown in Figures 2(c), 2(d), and 2(e) can be attributed to, (a) minimal gravity-associated segregation due to judicious selection of stirring parameters [13], (b) good wetting of TiC nanoparticles by the alloy matrix [16-19], (c) argon gas disintegration of metallic stream [20], and (d) dynamic deposition of composite slurry on substrate followed by hot extrusion. Similar reasonably uniform distribution of oxide nanoparticles (within the grain and at the grain boundary) in magnesium alloy ZK60A has also been recently reported [19]. In the nanocomposite, no reaction products based on $\mathrm{Mg}$ (or $\mathrm{Al}$ ) and $\mathrm{TiC}$ (such as $\mathrm{Mg}_{2} \mathrm{C}_{3}, \mathrm{Al}_{4} \mathrm{C}_{3}$ or Al-Ti based intermetallic in this case) having more than $2 \%$ by volume were detected using X-ray diffraction analysis.

\subsection{Mechanical Behavior}

4.3.1. Hardness. A significant increase in microhardness by $16 \%$ was observed in the nanocomposite when compared to monolithic material as listed in Table 1. This was consistent with earlier observations made on $\mathrm{Mg} / \mathrm{Al}_{2} \mathrm{O}_{3}, \mathrm{AZ31} / \mathrm{C}_{60}$ and AZ31/MWCNT nanocomposites [21-23]. The increase in hardness of the nanocomposite in the present study can be attributed to (a) reasonably uniform distribution of harder TiC nanoparticles in the matrix and (b) higher constraint to localized matrix deformation during indentation due to the presence of nanoparticles $[21,22,24]$.

4.3.2. Tensile and Compressive Behavior. The tensile and compressive strengths of monolithic material and nanocomposite are listed in Tables 3 and 4 (and shown in Figures 4(a) and $4(\mathrm{~b})$ ), respectively. $0.2 \%$ TYS and UTS were enhanced by $14 \%$ and 7\%, respectively, in AZ31/AZ91/1.5vol\% TiC compared to monolithic material. In comparison of compressive strengths, $0.2 \%$ CYS and UCS of AZ31/AZ91/1.5vol\% $\mathrm{TiC}$ were lower and higher by $11 \%$ and $7 \%$, respectively, compared to monolithic AZ31/AZ91. However, the compressive stress detected at any given strain was similar for AZ31/AZ91/1.5vol\% TiC and monolithic AZ31/AZ91 as shown in Figure 4(b). The tensile strength and UCS increase in AZ31/AZ91/1.5vol\% TiC compared to monolithic AZ31/AZ91 can be attributed to the following well-known factors (pertaining to reinforcement): (a) dislocation generation due to elastic modulus mismatch and coefficient of 


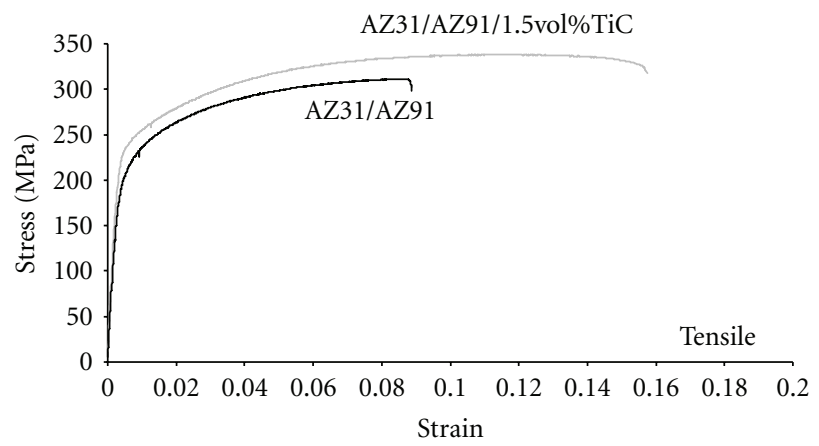

(a)

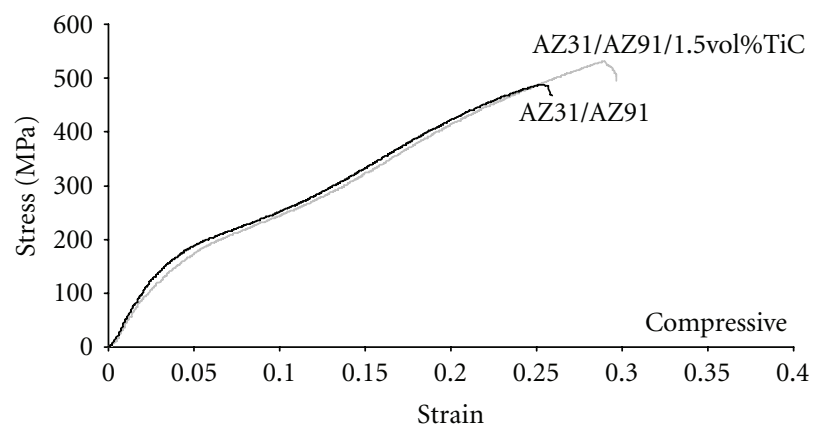

(b)

FIGURE 4: Representative: (a) tensile and (b) compressive stress-strain curves of monolithic AZ31/AZ91 and AZ31/AZ91/TiC nanocomposite.

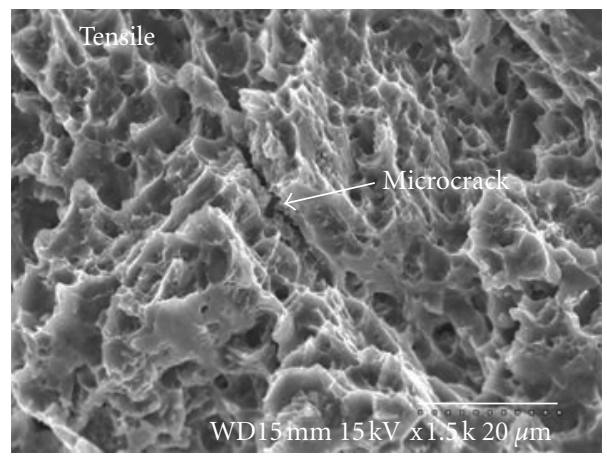

(a)

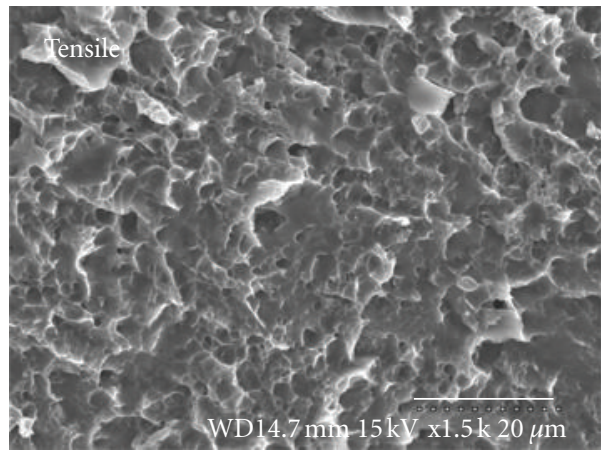

(b)

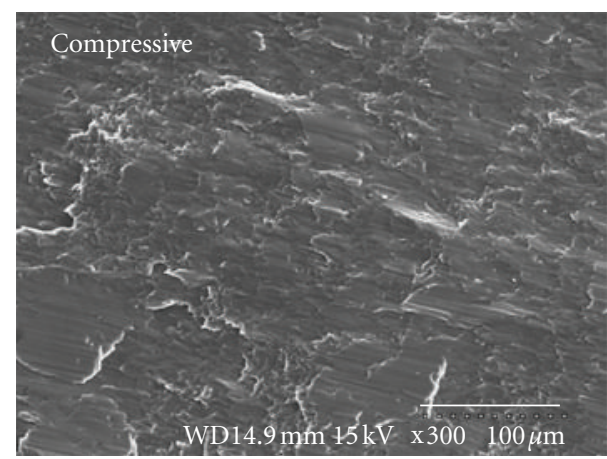

(c)

FIGURE 5: Representative tensile fractographs of (a) monolithic AZ31/AZ91 and (b) AZ31/AZ91/TiC nanocomposite. (c) Representative compressive fractograph of monolithic AZ31/AZ91 and AZ31/AZ91/TiC nanocomposite.

TABLE 3: Results of tensile testing of AZ31/AZ91 and AZ31/AZ91/TiC nanocomposite.

\begin{tabular}{|c|c|c|c|c|}
\hline Material & $\begin{array}{l}0.2 \% \text { TYS } \\
(\mathrm{MPa})\end{array}$ & $\begin{array}{c}\text { UTS } \\
(\mathrm{MPa})\end{array}$ & $\begin{array}{l}\text { Plastic failure strain } \\
(\%)\end{array}$ & $\begin{array}{c}\text { WOF } \\
\left(\mathrm{MJ} / \mathrm{m}^{3}\right)^{\mathrm{a}}\end{array}$ \\
\hline AZ31/AZ91 & $207 \pm 4$ & $316 \pm 6$ & $8.0 \pm 0.1$ & $24 \pm 0$ \\
\hline AZ31/AZ91/1.5vol\% TiC & $236 \pm 8(+14)$ & $337 \pm 7(+7)$ & $14.5 \pm 0.7(+81)$ & $46 \pm 2(+92)$ \\
\hline
\end{tabular}

abtained from engineering stress-strain diagram using EXCEL software.

() Brackets: indicate \% change with respect to corresponding result of AZ31/AZ91. 


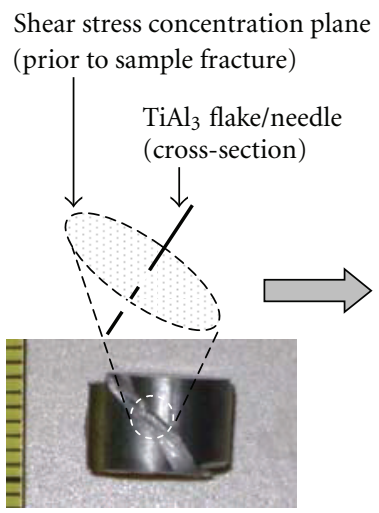

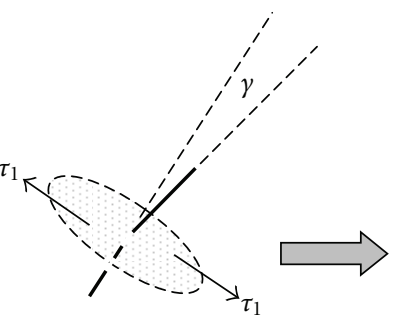

$\mathrm{TiAl}_{3}$ flake/needle (cross-section) buckling

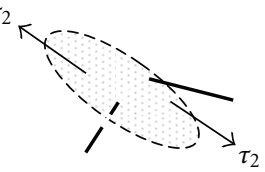

$\mathrm{TiAl}_{3}$ flake/needle (cross-section) fracture

Shear fractured compression sample

FIgURE 6: Schematic diagram illustrating compressive shear buckling of brittle $\mathrm{TiAl}_{3}$ flake/needle in AZ31/AZ91/TiC nanocomposite. $\tau_{1}$ and $\tau_{2}$ represent planar shear stresses where $\tau_{1}<\tau_{2} \cdot \gamma$ (exaggerated) represents very low angular deflection of the brittle TiAl $\mathrm{flake}$ needle during buckling.

TABLE 4: Results of compressive testing of AZ31/AZ91 and AZ31/AZ91/TiC nanocomposite.

\begin{tabular}{|c|c|c|c|c|}
\hline Material & $\begin{array}{c}0.2 \% \mathrm{CYS} \\
(\mathrm{MPa})\end{array}$ & $\begin{array}{c}\text { UCS } \\
(\mathrm{MPa}) \\
\end{array}$ & $\begin{array}{l}\text { Plastic failure strain } \\
(\%)\end{array}$ & $\begin{array}{c}\text { WOF } \\
\left(\mathrm{MJ} / \mathrm{m}^{3}\right)^{\mathrm{a}}\end{array}$ \\
\hline AZ31/AZ91 & $117 \pm 15$ & $495 \pm 13$ & $19.6 \pm 1.9$ & $82 \pm 6$ \\
\hline AZ31/AZ91/1.5vol\% TiC & $104 \pm 13(-11)$ & $531 \pm 11(+7)$ & $20.3 \pm 2.7(+4)$ & $94 \pm 2(+15)$ \\
\hline
\end{tabular}

abtained from engineering stress-strain diagram using EXCEL software.

() Brackets: indicate \% change with respect to corresponding result of AZ31/AZ91.

thermal expansion mismatch between the matrix and reinforcement $[22,23,25,26]$, (b) Orowan strengthening mechanism [25-27], and (c) load transfer from matrix to reinforcement $[22,25]$. The slight decrease in $0.2 \%$ CYS of AZ31/ AZ91/1.5vol\% TiC compared to monolithic AZ31/AZ91 can be attributed possibly to compressive shear buckling of brittle $\mathrm{TiAl}_{3}$ flakes/needles (occurring in trace amounts undetectable by XRD and possibly too fine to be observed using scanning electron microscopy) in AZ31/AZ91/1.5vol\% TiC as illustrated in Figure 6. Regarding this compressive shear buckling, it has been previously reported that the $\mathrm{TiAl}_{3}$ phase forms as brittle flakes/needles in solidification processed AlTi master alloys [28] and squeeze cast and heat treated $\mathrm{Al} /$ $\mathrm{TiO}_{2}$ composite [29]. The $\mathrm{TiAl}_{3}$ phase has been reportedly formed in $\mathrm{Al} / \mathrm{TiC}$ composites as well $[30,31]$. It has also been previously reported that $\mathrm{Mg}$ lowers the temperature of $\mathrm{TiAl}_{3}$ phase formation (catalyses $\mathrm{TiAl}_{3}$ phase formation) in $\mathrm{Mg}$ - $\mathrm{Al}$ Ti systems [32]. Further, the needle-like morphology of the $\mathrm{TiAl}_{3}$ phase has been strongly attributed (theoretically and experimentally) to its anisotropic valence electron structure (VES) [33]. The compressive shear buckling of brittle $\mathrm{TiAl}_{3}$ flakes/needles induces a slightly lower limit on the factors pertaining to reinforcement (as just described).

In both AZ31/AZ91/1.5vol\% TiC and monolithic AZ31/ AZ91, 0.2\% TYS was about 2.27 and 1.77 times the $0.2 \%$ CYS, respectively. Here, the tensile/compressive yield stress anisotropy $(0.2 \%$ TYS $/ 0.2 \%$ CYS $)$ was present despite the crystallographic texture exhibited where $\left\{\begin{array}{llllll}1 & 0 & 1 & -2\end{array}\right\}\left\langle\begin{array}{lllll}1 & 0 & 1 & -1\end{array}\right\rangle$ type twinning was activated along the $c$-axis of the HCP unit cell in Figure 3 with comparatively similar ease in both tension and compression along the $c$-axis, based on the $45^{\circ}$ angle between the $c$-axis and the vertical axis $[34,35]$. The tensile/compressive yield stress anisotropy $(0.2 \%$ TYS $/ 0.2 \%$ CYS) can be attributed generally to half the strain rate used (less strain hardening) in compressive testing compared to tensile testing. The tensile/compressive yield stress anisotropy was higher for AZ31/AZ91/1.5vol\% TiC compared to monolithic AZ31/AZ91 (2.27 compared to 1.77, resp.). This was similar to that observed in the case of ZK60A/1.0vol\% CNT compared to monolithic ZK60A (1.64 compared to 1.27, resp.) as recently reported [36]. This can be attributed possibly to compressive shear buckling of brittle $\mathrm{TiAl}_{3}$ flakes/ needles (occurring in trace amounts undetectable by XRD) in AZ31/AZ91/1.5vol\% TiC as illustrated in Figure 6. The brittle $\mathrm{TiAl}_{3}$ flake/needle is prone to buckling followed by fracture within the AZ31/AZ91 matrix during compressive deformation unlike during tensile deformation.

The tensile and compressive failure strains of monolithic material and nanocomposite are listed in Tables 3 and 4 (and based on stress-strain curves shown in Figures 4(a) and 4(b)), respectively. Compared to monolithic material, tensile failure strain was enhanced (+81\%) in AZ31/AZ91/1.5vol\% TiC. Compared to monolithic material, compressive failure strain was higher $(+4 \%)$ in AZ31/AZ91/1.5vol\% TiC. The significant tensile failure strain increase in AZ31/AZ91/ $1.5 \mathrm{vol} \% \mathrm{TiC}$ compared to monolithic AZ31/AZ91 can be attributed (pertaining to reinforcement) to the presence and reasonably uniform distribution of ceramic nanoparticles $[21,37]$. Here, it has been shown in previous studies that the nanoparticles provide sites where cleavage cracks are opened 
ahead of the advancing crack front. This cleavage crack opening dissipates the stress concentration that would otherwise exist at the crack front and alters the local effective stress state from plane strain to plane stress in the neighbourhood of the crack tip [21, 37]. In comparison of compressive failure strain, this effect was played down considering the crackclosing nature of compressive deformation, leading to only slightly higher (+4\%) failure strain in AZ31/AZ91/1.5vol\% TiC.

Tensile fracture behaviour of both monolithic material and nanocomposite was mixed (ductile + brittle) as shown in Figures 5(a) and 5(b). However, the tensile fractured surface of the nanocomposite had higher occurrence of smaller dimple-like features and absence of microcracks, compared to that of monolithic material. The tensile cavitation resistance was lower, and the microcrack formation resistance was higher in the nanocomposite compared to monolithic material. Compressive fracture behavior of AZ31/AZ91/1.5vol\% TiC was relatively similar (similar fracture surface exhibited) compared to monolithic material as shown in Figure 5(c). In this case where the $l / d$ ratio of samples was relatively low $(l / d=1)[38]$, the samples failed in shear and not by buckling as illustrated in recent work $[39,40]$.

The tensile and compressive work of fracture (WOF) of monolithic material and nanocomposite are listed in Tables 3 and 4 (and illustrated in Figures 4(a) and 4(b)), respectively. WOF quantified the ability of the material to absorb energy up to fracture under load [41]. Compared to monolithic material, tensile WOF was enhanced (+92\%) in AZ31/AZ91/1.5vol\% TiC. Compared to monolithic material, compressive WOF was increased $(+15 \%)$ in AZ31/AZ91/ $1.5 \mathrm{vol} \% \mathrm{TiC}$. The significantly high increment in tensile WOF and increment in compressive WOF exhibited by AZ31/AZ91/1.5vol\% TiC show its potential to be used in damage-tolerant design.

\section{Conclusions}

(1) Monolithic AZ31/AZ91 and AZ31/AZ91/1.5vol\% TiC nanocomposite can be successfully synthesized using the DMD technique followed by hot extrusion.

(2) Compared to monolithic AZ31/AZ91, tensile (yield and ultimate) and compressive (only ultimate) strengths of AZ31/AZ91/1.5vol\% TiC were each enhanced. This can be attributed to well-known factors pertaining to reinforcement. Compared to monolithic AZ31/AZ91, compressive (only yield) strength of AZ31/AZ91/1.5vol\% TiC was slightly decreased. This can be attributed possibly to compressive shear buckling of brittle $\mathrm{TiAl}_{3}$ flakes/needles (occurring in trace amounts) in the nanocomposite.

(3) Compared to monolithic AZ31/AZ91, tensile and compressive failure strain of AZ31/AZ91/1.5vol\% $\mathrm{TiC}$ were significantly enhanced and slightly increased, respectively. The significant enhancement of tensile failure strain can be attributed to the presence and reasonably uniform distribution of TiC nanoparticles. This effect was played down considering the crack-closing nature of compressive deformation, leading to only slightly increased compressive failure strain of AZ31/AZ91/1.5vol\% TiC.

(4) Compared to monolithic AZ31/AZ91, AZ31/AZ91/ $1.5 \mathrm{vol} \%$ TiC exhibited significantly high increment in tensile WOF and increment in compressive WOF.

\section{Acknowledgments}

The authors wish to acknowledge the National University of Singapore (NUS) and Temasek Defence Systems Institute (TDSI) for funding this research (TDSI/09-011/1A and WBS\# R265000349).

\section{References}

[1] M. M. Avedesian and H. Baker, ASM Specialty Handbook: Magnesium and Magnesium Alloys, ASM International, Materials Park, Ohio, USA, 1999.

[2] Y. Morisada, H. Fujii, T. Nagaoka, and M. Fukusumi, "Effect of friction stir processing with $\mathrm{SiC}$ particles on microstructure and hardness of AZ31," Materials Science and Engineering A, vol. 433, no. 1-2, pp. 50-54, 2006.

[3] Y. Morisada, H. Fujii, T. Nagaoka, and M. Fukusumi, "Nanocrystallized magnesium alloy-uniform dispersion of $\mathrm{C}_{60}$ molecules," Scripta Materialia, vol. 55, no. 11, pp. 1067-1070, 2006.

[4] Y. Morisada, H. Fujii, T. Nagaoka, and M. Fukusumi, "MWCNTs/AZ31 surface composites fabricated by friction stir processing," Materials Science and Engineering A, vol. 419, no. 1-2, pp. 344-348, 2006.

[5] M. J. Zhao, L. Z. Zhao, B. F. Zhou, and H. Yan, "Fabrication of AZ61-1.0\%Y antiburning magnesium semisolid slurry," Transactions of Nonferrous Metals Society of China, vol. 20, no. 2, pp. s476-s480, 2010.

[6] C. J. Lee, J. C. Huang, and P. J. Hsieh, "Mg based nano-composites fabricated by friction stir processing," Scripta Materialia, vol. 54, no. 7, pp. 1415-1420, 2006.

[7] X. J. Wang, X. S. Hu, K. Wu et al., "Hot deformation behavior of SiCp/AZ91 magnesium matrix composite fabricated by stir casting," Materials Science and Engineering A, vol. 492, no. 1-2, pp. 481-485, 2008.

[8] C. Badini, M. Ferraris, and F. Marchetti, "Interfacial reaction in AZ61/AZ91/P100 Mg/graphite composite: an Auger spectroscopy investigation," Materials Letters, vol. 21, no. 1, pp. 5561, 1994.

[9] D. Vallauri, I. C. Atías Adrián, and A. Chrysanthou, “TiC-TiB2 composites: a review of phase relationships, processing and properties," Journal of the European Ceramic Society, vol. 28, no. 8, pp. 1697-1713, 2008.

[10] A. Contreras, C. Angeles-Chávez, O. Flores, and R. Perez, "Structural, morphological and interfacial characterization of Al-Mg/TiC composites," Materials Characterization, vol. 58, no. 8-9, pp. 685-693, 2007.

[11] Y. Chen, Y. C. Wu, F. W. Yu, and J. L. Chen, "Microstructure and mechanical properties of tungsten composites costrengthened by dispersed $\mathrm{TiC}$ and $\mathrm{La}_{2} \mathrm{O}_{3}$ particles," International Journal of Refractory Metals and Hard Materials, vol. 26, no. 6, pp. 525-529, 2008.

[12] J. J. Wang, J. H. Guo, and L. Q. Chen, “TiC/AZ91D composites fabricated by in situ reactive infiltration process and its tensile 
deformation," Transactions of Nonferrous Metals Society of China, vol. 16, no. 4, pp. 892-896, 2006.

[13] L. M. Tham, M. Gupta, and L. Cheng, "Influence of processing parameters during disintegrated melt deposition processing on near net shape synthesis of aluminium based metal matrix composites," Materials Science and Technology, vol. 15, no. 10, pp. 1139-1146, 1999.

[14] M. Gupta, M. O. Lai, and S. C. Lim, "Regarding the processing associated microstructure and mechanical properties improvement of an Al-4.5 Cu alloy," Journal of Alloys and Compounds, vol. 260, no. 1-2, pp. 250-255, 1997.

[15] M. Paramsothy, S. F. Hassan, N. Srikanth, and M. Gupta, "Adding carbon nanotubes and integrating with AA5052 aluminium alloy core to simultaneously enhance stiffness, strength and failure strain of AZ31 magnesium alloy," Composites Part A, vol. 40, no. 9, pp. 1490-1500, 2009.

[16] B. Q. Han and D. C. Dunand, "Microstructure and mechanical properties of magnesium containing high volume fractions of yttria dispersoids," Materials Science and Engineering A, vol. 277, no. 1-2, pp. 297-304, 2000.

[17] N. Eustathopoulos, M. G. Nicholas, and B. Drevet, Wettability at High Temperatures, vol. 3 of Pergamon Materials Series, Pergamon Press, New York, NY, USA, 1999.

[18] J. D. Gilchrist, Extraction Metallurgy, Pergamon Press, New York, NY, USA, 3rd edition, 1989.

[19] M. Paramsothy, J. Chan, R. Kwok, and M. Gupta, "The effective reinforcement of magnesium alloy ZK60A using $\mathrm{Al}_{2} \mathrm{O}_{3}$ nanoparticles," Journal of Nanoparticle Research, vol. 13, no. 10, pp. 4855-4866, 2011.

[20] M. Gupta, M. O. Lai, and C. Y. Soo, "Effect of type of processing on the micro structural features and mechanical properties of $\mathrm{Al}-\mathrm{Cu} / \mathrm{SiC}$ metal matrix composites," Materials Science and Engineering A, vol. 210, no. 1-2, pp. 114-122, 1996.

[21] S. F. Hassan and M. Gupta, "Effect of particulate size of $\mathrm{Al}_{2} \mathrm{O}_{3}$ reinforcement on microstructure and mechanical behavior of solidification processed elemental Mg," Journal of Alloys and Compounds, vol. 419, no. 1-2, pp. 84-90, 2006.

[22] S. F. Hassan and M. Gupta, "Effect of different types of nanosize oxide participates on microstructural and mechanical properties of elemental Mg," Journal of Materials Science, vol. 41, no. 8, pp. 2229-2236, 2006.

[23] S. F. Hassan and M. Gupta, "Enhancing physical and mechanical properties of $\mathrm{Mg}$ using nanosized $\mathrm{Al}_{2} \mathrm{O}_{3}$ particulates as reinforcement," Metallurgical and Materials Transactions A, vol. 36, no. 8, pp. 2253-2258, 2005.

[24] C. S. Goh, J. Wei, L. C. Lee, and M. Gupta, "Development of novel carbon nanotube reinforced magnesium nanocomposites using the powder metallurgy technique," Nanotechnology, vol. 17, no. 1, pp. 7-12, 2006.

[25] Z. Száraz, Z. Trojanová, M. Cabbibo, and E. Evangelista, "Strengthening in a WE54 magnesium alloy containing SiC particles," Materials Science and Engineering A, vol. 462, no. 1-2, pp. 225-229, 2007.

[26] L. H. Dai, Z. Ling, and Y. L. Bai, "Size-dependent inelastic behavior of particle-reinforced metal-matrix composites," Composites Science and Technology, vol. 61, no. 8, pp. 1057-1063, 2001.

[27] D. Hull and D. J. Bacon, Introduction to Dislocations, Butterworth-Heinemann, Oxford, UK, 4th edition, 2002.

[28] H. Y. Wang, Q. C. Jiang, Y. Q. Zhao, F. Zhao, B. X. Ma, and Y. Wang, "Fabrication of $\mathrm{TiB}_{2}$ and $\mathrm{TiB}_{2}$-TiC particulates reinforced magnesium matrix composites," Materials Science and Engineering A, vol. 372, no. 1-2, pp. 109-114, 2004.
[29] H. X. Peng, D. Z. Wang, L. Geng, C. K. Yao, and J. F. Mao, "Evaluation of the microstructure of in-situ reaction processed $\mathrm{Al}_{3} \mathrm{Ti}^{-} \mathrm{Al}_{2} \mathrm{O}_{3}-\mathrm{Al}$ composite," Scripta Materialia, vol. 37, no. 2, pp. 199-204, 1997.

[30] V. H. López, A. R. Kennedy, and J. Lemus, "Characterization of the reactivity in Al-10wt.\% TiC metal matrix composites by image analysis," Kovove Materialy, vol. 48, no. 1, pp. 17-24, 2010.

[31] K. Satyaprasad, Y. R. Mahajan, and V. V. Bhanuprasad, "Strengthening of Al/20 v/o TiC composites by isothermal heat treatment," Scripta Metallurgica et Materiala, vol. 26, no. 5, pp. 711-716, 1992.

[32] Z. R. Yang, S. Q. Wang, X. H. Cui, Y. T. Zhao, M. J. Gao, and M. X. Wei, "Formation of $\mathrm{Al}_{3} \mathrm{Ti} / \mathrm{Mg}$ composite by powder metallurgy of Mg-Al-Ti system," Science and Technology of Advanced Materials, vol. 9, no. 3, Article ID 035005, 2008.

[33] Y. Ye, P. Li, and L. He, "Valence electron structure analysis of morphologies of $\mathrm{Al}_{3} \mathrm{Ti}$ and $\mathrm{Al}_{3} \mathrm{Sc}$ in aluminum alloys," Intermetallics, vol. 18, no. 2, pp. 292-297, 2010.

[34] T. Laser, C. Hartig, M. R. Nürnberg, D. Letzig, and R. Bormann, "The influence of calcium and cerium mischmetal on the microstructural evolution of Mg-3Al-1Zn during extrusion and resulting mechanical properties," Acta Materialia, vol. 56, no. 12, pp. 2791-2798, 2008.

[35] J. Bohlen, S. B. Yi, J. Swiostek, D. Letzig, H. G. Brokmeier, and K. U. Kainer, "Microstructure and texture development during hydrostatic extrusion of magnesium alloy AZ31," Scripta Materialia, vol. 53, no. 2, pp. 259-264, 2005.

[36] M. Paramsothy, J. Chan, R. Kwok, and M. Gupta, "Addition of CNTs to enhance tensile/compressive response of magnesium alloy ZK60A," Composites Part A, vol. 42, no. 2, pp. 180-188, 2011.

[37] S. F. Hassan and M. Gupta, "Development of nano- $\mathrm{Y}_{2} \mathrm{O}_{3}$ containing magnesium nanocomposites using solidification processing," Journal of Alloys and Compounds, vol. 429, no. 1-2, pp. 176-183, 2007.

[38] D. J. Towle and C. M. Friend, "Comparison of compressive and tensile properties of magnesium based metal matrix composites," Materials Science and Technology, vol. 9, no. 1, pp. 35-41, 1993.

[39] M. Paramsothy, N. Srikanth, S. F. Hassan, and M. Gupta, "Heat-treating below recrystallization temperature to enhance compressive failure strain and work of fracture of magnesium," Materials Science and Engineering A, vol. 494, no. 1-2, pp. 436-444, 2008.

[40] M. Paramsothy, S. F. Hassan, N. Srikanth, and M. Gupta, "Enhancement of compressive strength and failure strain in AZ31 magnesium alloy," Journal of Alloys and Compounds, vol. 482, no. 1-2, pp. 73-80, 2009.

[41] R. E. Reed-Hill, Physical Metallurgy Principles, D Van Nostrand, New York, NY, USA, 2nd edition, 1964. 

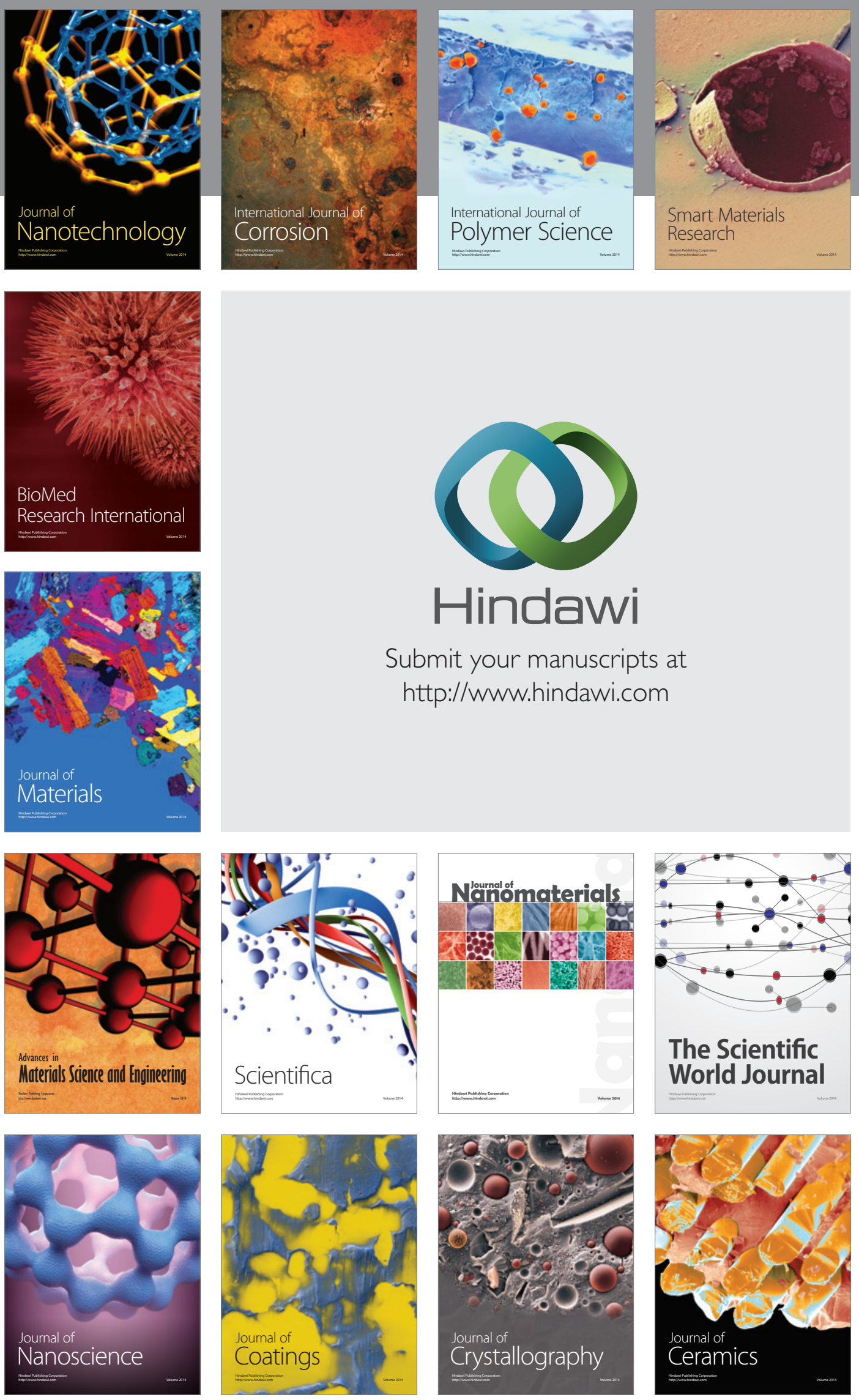

The Scientific World Journal

Submit your manuscripts at

http://www.hindawi.com

\section{World Journal}

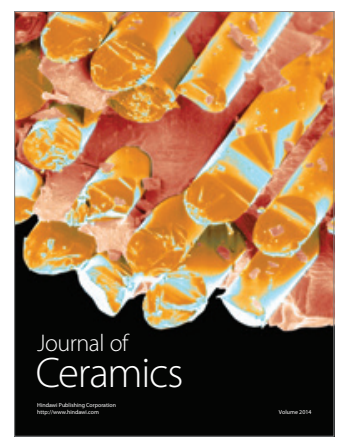

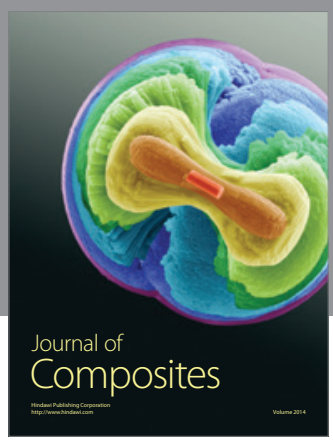
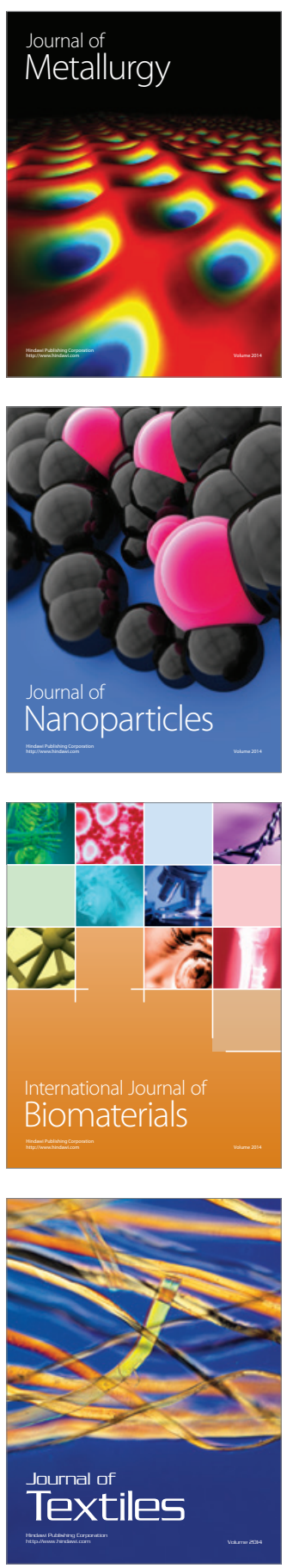